\title{
The Mars Science Laboratory Organic Check Material
}

\author{
Pamela G. Conrad • Jennifer L. Eigenbrode • Max O. Von der Heydt • \\ Claus T. Mogensen · John Canham • Dan N. Harpold • Joel Johnson • Therese Errigo • \\ Daniel P. Glavin · Paul R. Mahaffy
}

Received: 6 January 2012 / Accepted: 2 May 2012 / Published online: 12 June 2012

(C) The Author(s) 2012. This article is published with open access at Springerlink.com

\begin{abstract}
Mars Science Laboratory's Curiosity rover carries a set of five external verification standards in hermetically sealed containers that can be sampled as would be a Martian rock, by drilling and then portioning into the solid sample inlet of the Sample Analysis at Mars (SAM) suite. Each organic check material (OCM) canister contains a porous ceramic solid, which has been doped with a fluorinated hydrocarbon marker that can be detected by SAM. The purpose of the OCM is to serve as a verification tool for the organic cleanliness of those parts of the sample chain that cannot be cleaned other than by dilution, i.e., repeated sampling of Martian rock. SAM possesses internal calibrants for verification of both its performance and its internal cleanliness, and the OCM is not used for that purpose. Each OCM unit is designed for one use only, and the choice to do so will be made by the project science group (PSG).
\end{abstract}

Keywords Mars · Mars science laboratory · MSL · SAM · Organic check material · OCM $\cdot$ Contamination $\cdot$ Sample chain

\section{Introduction}

The Mars Science Laboratory (MSL) mission will investigate the habitability potential of Gale Crater, a location near the martian equator at $4^{\circ} 36^{\prime} 0^{\prime \prime} \mathrm{S}, 137^{\circ} 12^{\prime} 0^{\prime \prime} \mathrm{E}$ (Grotzinger et al.

P.G. Conrad ( $\varangle)$ · J.L. Eigenbrode · D.N. Harpold · T. Errigo · D.P. Glavin · P.R. Mahaffy Planetary Environments Laboratory Code 699, NASA Goddard Space Flight Center, Bldg 33, Rm C105, 8800 Greenbelt Road, Greenbelt, MD 20771, USA e-mail: Pamela.G.Conrad@nasa.gov

M.O. Von der Heydt · C.T. Mogensen · J. Johnson Jet Propulsion Laboratory, California Institute of Technology, Pasadena, CA, USA

Present address:

C.T. Mogensen

Grundfos Management AS, Bjerringbro, Denmark

J. Canham

ATK Space Systems Inc., Beltsville, MD, USA 
2012). This location has been advanced as a potential target of astrobiological significance (Cabrol et al. 1999; Pelkey and Jakosky 2002; Pelkey et al. 2004). To contemplate the daunting task of evaluating whether the planet is presently or was formerly capable of supporting life, assumptions must be made regarding the requirements for habitable environments based upon what we find associated with life on Earth. Factors such as water, a source of energy and organic (hydrocarbon) compounds are well-accepted evidence of an environment's potential to allow the sustenance of life on Earth, and they will be important criteria for the evaluation of habitability potential at Gale crater through time as interpreted in the investigation of Gale's deep stratigraphic record. The nature and distribution of organic material on Mars is of particular interest because while there are tantalizing clues (e.g., Mumma et al. 2009) of methane in the martian atmosphere, and a presumed in-fall of organic material by meteorite to the surface, we do not presently know whether the conditions on the martian surface or shallow subsurface will allow organic chemical reactions that would be necessary for life to take place. We do know that the surface of Mars appears to be an extremely oxidizing environment, so an important first order question to be answered is whether there is or was enough range in the redox potential of martian surface environments to allow for the preservation of reduced carbon phases somewhere in the stratigraphic record that is available to us at Gale Crater.

Mars Science Laboratory is equipped with instruments that can make a variety of chemical measurements, including sensitive detections of organic chemicals and the ratios of key isotopes with astrobiological significance. The payload is described in detail in the other articles in this issue. The investigation that will conduct a detailed molecular inventory of the solid samples that Curiosity is directed to acquire is The Sample Analysis at Mars (SAM) experiment. SAM is a trio of instruments - quadrupole mass spectrometer (QMS), gas chromatograph (GC) and tunable laser spectrometer (TLS) that are supported by a multiple sample manipulation system and a flexible gas processing system with two high temperature $\left(1000^{\circ} \mathrm{C}\right.$ ) pyrolysis ovens (Mahaffy et al. 2012). The SAM suite is also equipped with chemical extraction capability for a limited number of samples (nine) so that organic molecules not readily detected by pyrolysis might be derivatized and thus detectable by SAM, e.g. amino acids and nucleobases. The performance of SAM is such that it is capable of detecting very trace quantities of hydrocarbons, thus if there were organic contaminants either within the instrument system or elsewhere in the sample chain, they could mask potentially detectable analytes. So it is important to maintain a very high level of organic cleanliness (better than 40 ppbv) along the sample chain. While the SAM suite can bake itself out, the external parts of the sample chain cannot (drill, portioner, scoop and the SAM solid sample inlet tubes (SSIT) or their covers), hence their cleanliness must be periodically evaluated in some way in order to understand SAM's findings with respect to organic materials on Mars.

In the Viking GCMS analyses, trace chloro-hydrocarbons were detected but originally thought to be products of solvents used to clean the hardware (Biemann et al. 1977). Now others have argued they could be products of perchlorate/organic matter chemistry in martian regolith (Navarro-Gonzalez et al. 2010). It is important to avoid such a situation with SAM/MSL. Note that Viking only had one oven to check GCMS background and no organic check material to understand sample path contamination.

Early in the mission planning process, the Mars Science Laboratory (MSL) science office convened an "Organic Blank Working Group" (OBWG) to address the question of whether or not the mission should carry some kind of calibrated standard that could be used as a "clean" chemical benchmark against which to understand the analyses of martian materials. ${ }^{1}$

\footnotetext{
${ }^{1}$ The study group was convened in April 2007 and consisted of M. Anderson (JPL analytical chemist), D. Blake (CheMin PI), P. Conrad (SAM co-I \& IS), J. Crisp (MSL Dep. Proj. Scientist), P. Mahaffy (SAM
} 
The group recommended that indeed some sort of "organic blank" be included with the MSL mission and the verifiable rationale was reported to the project science office along with draft requirements and suggestions for implementation. The recommendations can be summarized as follows:

1. In laboratory experiments, it is standard practice to first analyze a blank sample (that is, one free of detectable analytes), followed by a standard calibrant (Skoog et al. 2004).

2. The SAM investigation is able to detect trace levels of organic molecules, so the investigation must be able to distinguish between organic chemicals that might be found on Mars and contamination that traveled there with the spacecraft. The SAM investigation does carry internal calibrants (spiked blanks) against which to compare the internal parts of SAM that can be cleaned, excepting the SAM solid sample inlet tubes (SSIT). Without an external calibrant that can be contacted and processed by the rover's sampling system (SA-SPaH) and the SAM SSITs, there is no way to check for contamination associated with those parts of the sample chain.

3. If SAM were to detect organic molecules on Mars, this would be an important milestone in solar system exploration. Cleanliness of the spacecraft must be proven in order to determine that we are not detecting Earth-origin chemistry. So the sampling chain must be checked on Mars, because we must assume the possibility that the spacecraft materials could have undergone changes after launch and landing. Also, the martian environment is not identical to the conditions under which our pre-launch contamination testing was done, so it must be verified again in situ. The primary role of the MSL OCM is to clearly differentiate between terrestrial contamination and indigenous or meteoric martian materials. We must unambiguously verify the assumption that both SAM and the SA-SPaH are clean.

Six to ten organic check material samples are required to accurately assess levels of terrestrial contamination a few times during the baseline mission of one martian year. If only one OCM sample were to be flown, it could be used early in the mission if organic material is detected in a martian sample. This would leave MSL in a compromised position should the need for another OCM standard arise later in the mission, such as a suspected release of volatile contaminants or analysis of a solid sample containing new (as yet unobserved) organic compounds.

\section{Scientific Objective and Requirements}

The Organic Check Material is a verification tool for the organic cleanliness of those parts of the sample chain that cannot be cleaned other than by dilution with martian samples. By sample chain, we refer to everything that touches the sample before it arrives in a SAM sample cup, including SAM's solid sample inlet tubes (SSITs). In order to accomplish the verification, the OCM must be processed through the entire sample chain from drilling and portioning to delivery into SAM through its solid sample inlet tubes. The SAM instrument suite (Mahaffy et al. 2012, this issue) is capable of cleaning itself by heating, and then verifying its cleanliness by running evolved gas blanks from empty sample cups. However the SSITs and the external sample processing components, e.g., drill, sample-portioner and

PI), D. Ming (CheMin \& SAM Co-I), R. Morris (CheMin and SAM Co-I), A. Sessions (Caltech professor), R. Summons (MIT professor), R. Welch (MSL Dep. Proj. System Engineer). Ex-officio: E. Stolper (then MSL Proj. Scientist), M. Meyer (MSL Prog. Scientist). 
scoop cannot be baked out; they can only be cleaned by dilution-repeated processing of martian material with the assumption that this process will dilute any contamination in the external sample chain (including SSITs). The dilution process can only be verified with a SAM solid sample experiment, so a sample of unknown (or not yet verified) cleanliness would have to be ingested by SAM. Without having knowledge of the native inventory of possible organics in the martian samples, it would be difficult to know whether detected hydrocarbons are coming from the hardware or indigenous to the rock unless the putative contaminant were known to be produced only by non-naturally occurring processes. Evaluating the cleanliness of a sample with a known initial cleanliness is the way out of the ambiguity, and the OCM serves that purpose.

\subsection{Usage Concept}

The OCM is a very limited resource on MSL, so to invoke its use requires agreement by the project science group (PSG). If SAM were to make a detection of organic compounds in a martian sample, certainly that experiment would be repeated, and then confirmation that the detection is not some sort of terrestrial contamination would be required. On Earth, the convention is to run a standard in advance of the unknown to verify the condition of the analytical tool, however on Mars, each use of an instrument (and of the SA-SPaH) has some risk associated with it, so it becomes important to interrogate martian samples as a high priority. The SAM solid sample experiments include background scans of the QMS before introduction of solids (Mahaffy et al. 2012, this issue), so there are procedural "blanks" built into the SAM experiment, and when needed, its internal calibration standards can be analyzed. The OCM not employed as a verification tool for SAM performance, but only to determine that the external sample chain has not contaminated a martian sample that tests positive for organic compounds.

In that regard, if there is reason to suspect that the initial state of cleanliness of the external sample chain is poor, one might argue that it not be used until repeated dilution cleaning cycles are executed, and in that case, the OCM would be needed to verify the efficacy of the dilution cleaning (Anderson et al. 2012, this issue).

With respect to management of resources for the duration of the nominal mission, if organic compounds are found early in the mission or become commonly associated with a particular rock facies or mineral phase, the strategic plan for preserving one or two OCM units for late in the mission or perhaps an extended mission (if deemed likely) would have to be considered.

\subsection{Requirements}

The Organic Blank Working Group initially recommended that the OCM be crushed and somehow accessible to the soil scoop so that its cleanliness could also be verified, however this is not possible given the architecture of SA-SPaH. Curiosity's rotary-percussive drill powders the rock as it penetrates the target and it conducts the powders directly into the portioner. The scoop and drill are arranged on the end of the rover arm in such a way that it is not possible to sample the OCM with the drill and somehow place the powdered OCM into the scoop. Should the scooped samples repeatedly yield results suspected to be selfinduced contamination, the only path to verification would be elimination of other verifiable components in the sample chain and then an attempted mitigation by dilution cleaning.

It was reasoned early on that if a "blank" were to be ingested by SAM, a null result, or no detected organics could be interpreted either as a clean blank or as an experimental fault 
of some sort. The only way to remove that particular ambiguity is to spike the OCM with a detectable marker that is clearly not martian. However, introducing organic markers into the analytical pathway is a bit delicate. The compound cannot be too volatile or it could sublime during the drilling and portioning process before delivery into SAM. It cannot be too sticky, or it could remain in the SA-SPaH hardware or be too difficult to clean from SAM. Since the SA-SPaH hardware and the SAM SSITs can only be cleaned by dilution with other materials, the organic marker must not become a source of contamination for the martian samples to be subsequently analyzed. The "Goldilocks" set of properties would also include:

- thermal stability over the range of temperatures expected in cruise and on Mars both diurnally and seasonally

- resistance to attack by ionizing radiation over the nominal mission life time, including background galactic cosmic rays, solar energetic particles and UV radiation

- chemical compatibility with the inorganic matrix, e.g., non reactive and easily dispersed throughout the matrix compositional simplicity-avoids functional groups that could mask analytical targets of interest

Because of the requirement for processing the OCM like a martian sample, the bulk material also had constraining requirements. Clearly it should be readily distinguishable from martian mineral targets, so to the first order, it had to be chemically simple, avoiding key elements of interest, including $\mathrm{Ni}, \mathrm{Zn}, \mathrm{Cr}, \mathrm{K}, \mathrm{Y}, \mathrm{Sr}(<1 \%$ by wt.) and $\mathrm{Mn}(\leq 0.3 \%$ by wt. with a 2 hour integration by CheMin X-ray fluorescence measurement). The CheMin X-ray diffraction (and X-ray fluorescence) investigation (Blake et al. 2012) requested that the material be amorphous to avoid masking weak diffraction peaks of minerals. Other important constraints were:

- organically clean as verified by levels $<5 \mathrm{ppb}$ of detectable hydrocarbon upon pyrolysis to $900{ }^{\circ} \mathrm{C}$ in SAM

- the material must release no more than $0.1 \%$ of its mass in non-hydrocarbon volatiles upon pyrolysis to $900{ }^{\circ} \mathrm{C}$

- the material must have a compressive strength $<230 \mathrm{MPa}$ in order to avoid excessive wear on the SA-SPaH drill bits

- the material must have interconnected pore space in order to distribute the dopant throughout the material.

- The material must not present a hazard to the SA-SPaH hardware by splintering into shards that could damage the drill, seals or portioner

In summary, the OCM material had to be clean, possess a marker that could ensure its detectability by SAM, not interfere with the scientific targets of interest on Mars, and it had to last in its pristine state throughout the duration of the nominal mission, one martian year.

\section{Inorganic Matrix}

Several ceramics were considered as candidates for the OCM material (Table 1), and a fused silica was the initial choice. Fused silica has a very low coefficient of thermal expansion, which makes it robust to thermal cycling. The manufacturing process can include various trace components that affect its purity, and since specific vendors have proprietary processes, not all fused silicas share the same chemistry. 
Table 1 Ceramics considered for the inorganic matrix material

\begin{tabular}{|c|c|c|c|c|c|c|c|}
\hline Vendor & Brand & \multicolumn{2}{|c|}{$\begin{array}{l}\text { Composition } \\
\text { [wt.\%] }\end{array}$} & $\begin{array}{l}\text { Porosity } \\
{[\%]}\end{array}$ & $\begin{array}{l}\text { Compressive } \\
\text { strength } \\
{[\mathrm{MPa}]}\end{array}$ & $\begin{array}{l}\operatorname{Max} \mathrm{T} \\
{\left[{ }^{\circ} \mathrm{C}\right]}\end{array}$ & $\begin{array}{l}\rho \\
{\left[\mathrm{g} / \mathrm{cm}^{3}\right]}\end{array}$ \\
\hline Accuratus & $\begin{array}{l}\text { Accuflect B6 } \\
\text { Accuflect G6 } \\
\text { (glazed B6) }\end{array}$ & $\begin{array}{l}\mathrm{Al}_{2} \mathrm{O}_{3} \\
\mathrm{SiO}_{2} \\
\mathrm{MgO} \\
\mathrm{CaO} \\
\mathrm{Na}_{2} \mathrm{O} \\
\mathrm{Fe}_{2} \mathrm{O}_{3}\end{array}$ & $\begin{array}{c}95.5 \% \\
2.9 \% \\
1.1 \% \\
0.28 \% \\
0.15 \% \\
0.15 \%\end{array}$ & $\begin{array}{l}\text { 30, variable } \\
0 \text { (for glaze) }\end{array}$ & 62 & $\begin{array}{l}1200 \\
750 \\
\text { (for glaze) }\end{array}$ & 2.3 \\
\hline Aremco & Aremcolox 502-1400 & $\mathrm{Al}_{2} \mathrm{O}_{3}$ & & 25 & 62 & 1427 & 2.8 \\
\hline $\begin{array}{l}\text { Corning } \\
\text { glass }\end{array}$ & Porous vycor & $\begin{array}{l}\mathrm{SiO}_{2} \\
\mathrm{~B}_{2} \mathrm{O}_{3} \\
\mathrm{Al}_{2} \mathrm{O}_{3} \\
\mathrm{Na}_{2} \mathrm{O}\end{array}$ & $\begin{array}{r}96.0 \% \\
3.0 \% \\
<0.6 \% \\
0.4 \%\end{array}$ & 28 & & 1000 & 2.18 \\
\hline Cotronics & Rescor $310 M$ & $\begin{array}{l}\mathrm{SiO}_{2} \\
\mathrm{Al}_{2} \mathrm{O}_{3} \\
\mathrm{CaO} \\
\mathrm{Fe}_{2} \mathrm{O}_{3}\end{array}$ & $\begin{aligned}> & 99.5 \% \\
& 0.3 \% \\
< & 0.2 \% \\
< & 0.03 \%\end{aligned}$ & 63 , fixed & 8.3 & 1650 & 0.8 \\
\hline Filtros* & $\begin{array}{l}\text { FAO-10 }\left(\varnothing_{\text {pore }}=60\right) \\
\text { FAO-50 }\left(\varnothing_{\text {pore }}=140\right) \\
\text { FAO-100 }\left(\varnothing_{\text {pore }}=210\right)\end{array}$ & $\begin{array}{l}\mathrm{Al}_{2} \mathrm{O}_{3} \\
\mathrm{SiO}_{2} \\
\mathrm{TiO}_{2} \\
\mathrm{Br}_{2} \mathrm{O}_{3} \\
\mathrm{MgO} \\
\mathrm{Fe}_{2} \mathrm{O}_{3} \\
\mathrm{Na}_{2} \mathrm{O} \\
\mathrm{CaO}\end{array}$ & $\begin{array}{r}84.7 \% \\
10.0 \% \\
2.2 \% \\
1.1 \% \\
0.5 \% \\
0.5 \% \\
0.2 \% \\
0.1 \%\end{array}$ & 40 & variable & 1100 & 2.1 \\
\hline $\begin{array}{l}\text { HP } \\
\text { technical } \\
\text { ceramics }\end{array}$ & $\begin{array}{l}F S-120 \\
S L S-50\end{array}$ & $\begin{array}{l}\mathrm{SiO}_{2} \\
\mathrm{SiO}_{2}-\mathrm{C}\end{array}$ & $\mathrm{aO}-\mathrm{Na}_{2} \mathrm{O}$ & $\begin{array}{l}30, \text { variable } \\
30, \text { variable }\end{array}$ & 12 & $\begin{array}{l}1500 \text { but } \\
\text { softens } \\
\text { over } 1000\end{array}$ & 1.54 \\
\hline
\end{tabular}

Note that the organic blank material for the Phoenix mission (Ming et al. 2008), Macor MCG, was not considered as a viable candidate for the MSL OCM, primarily because of its high compressive strength, $344 \mathrm{MPa}$, which violates MSL drilling requirements. Moreover, because it is a fluorophlogopite mica embedded in a borosilicate glass matrix, it exhibits some degree of crystallinity with powder XRD, and it exceeds the required limit for potassium. Of the list of ten candidate materials in Table 1, five could be immediately dismissed because they were compositionally unsuitable. The other five were assayed to determine their degree of crystallinity by powder X-ray diffraction using a Bruker D-8 Discover diffractometer equipped with a copper X-ray source $(K \alpha, \lambda=0.1542 \mathrm{~nm})$ and a general area detector. They are noted by italicized names in Table 1 . The XRD characterizations showed corundum peaks with substantial intensity in the Accuflex B6 and the Aremcolox 502-1400, and the diffraction patterns of the other materials are normalized against the patterns of these two materials (Fig. 1). The most amorphous of the candidate materials was one of the porous ceramic silicas manufactured by H.P. Technical Ceramics, Sheffield, UK, FS-120. 

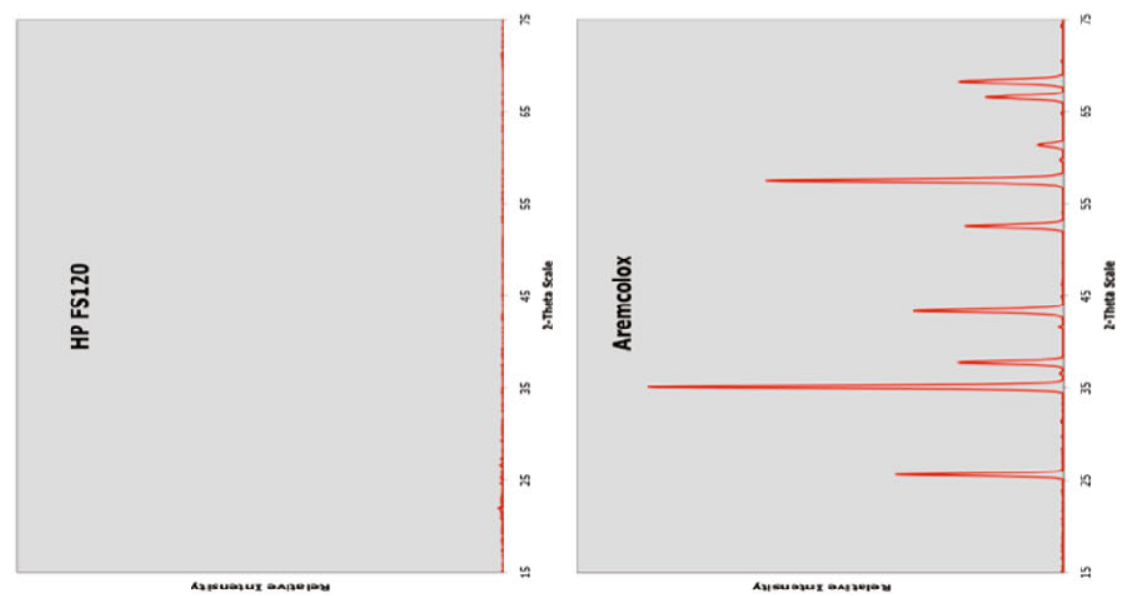

$\underset{7}{x}$

○

$\exists 8$

远

电

동

.

วิ
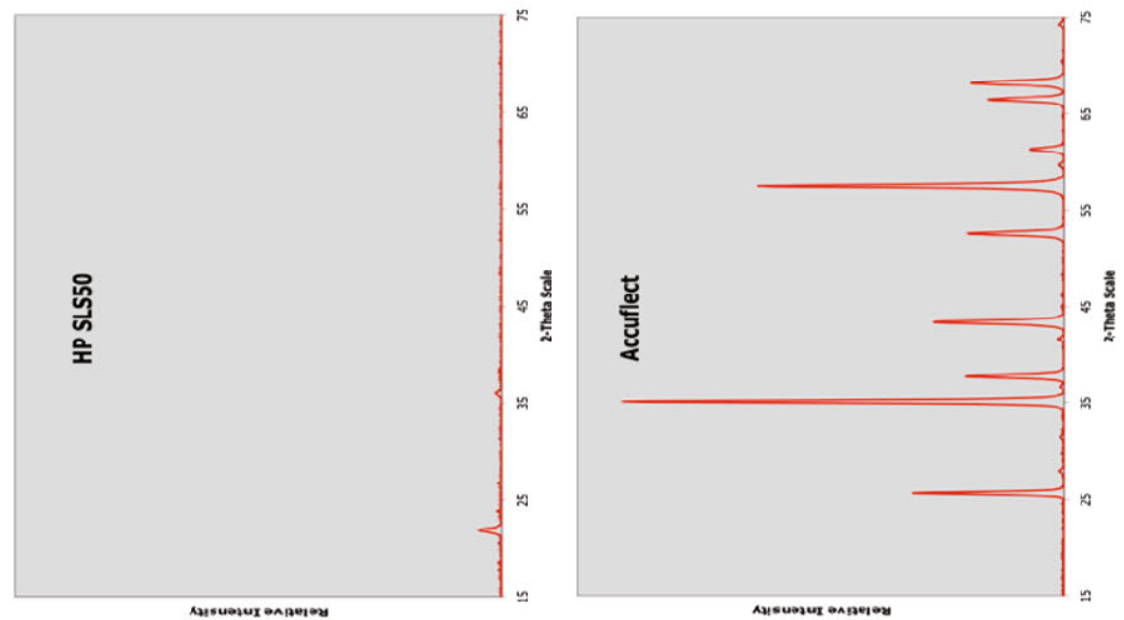

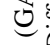

ฮี

事。

ธี ขิ

전

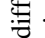

흔

跣

0

ฮี

주

림

$\pi$

站

응

원

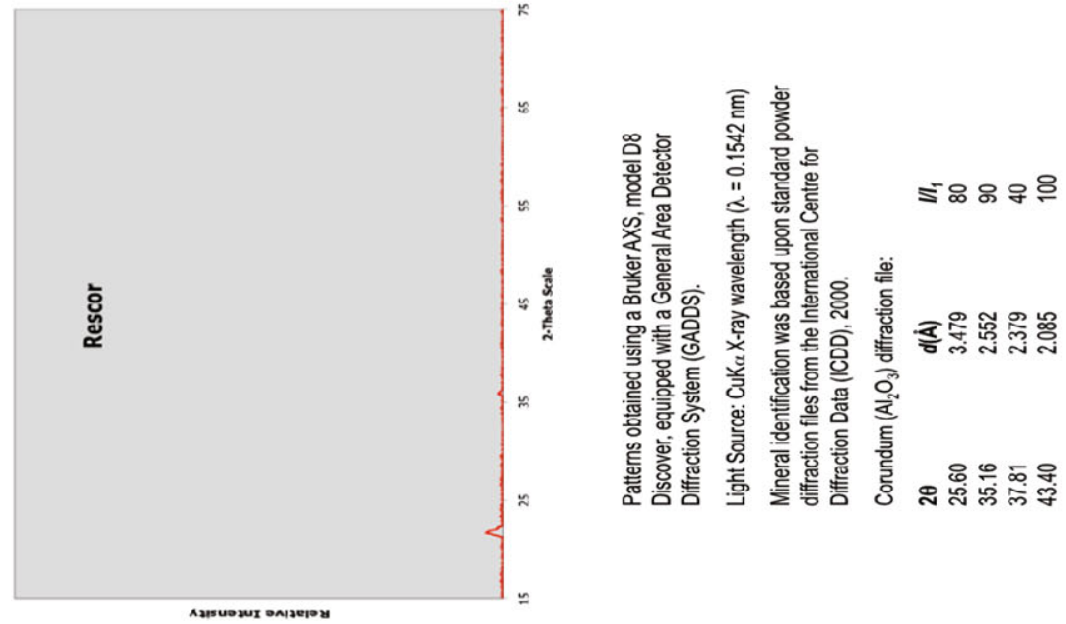


A

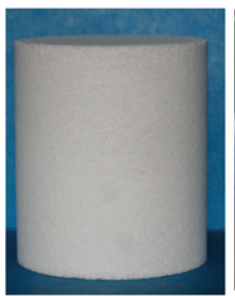

B

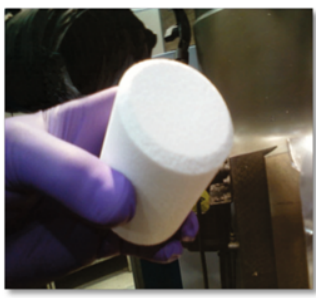

C

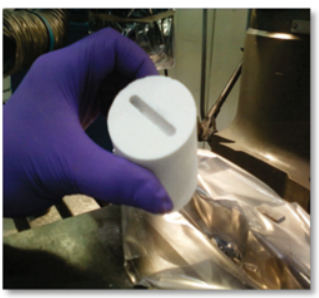

D

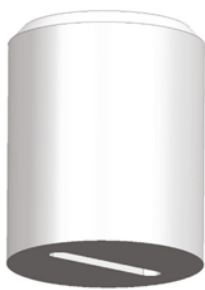

Fig. 2 The FS-120 ceramic material. Panel $\mathbf{A}$ is the un-machined brick. The dimensions are $76.74 \times 57.5 \mathrm{~mm}$. Panel $\mathbf{B}$ shows the top chamfered edge of the brick and Panel $\mathbf{C}$ shows the machined groove for the coupling plate in the bottom of the brick. Panel $\mathbf{D}$ is a drawing that illustrates all of the features

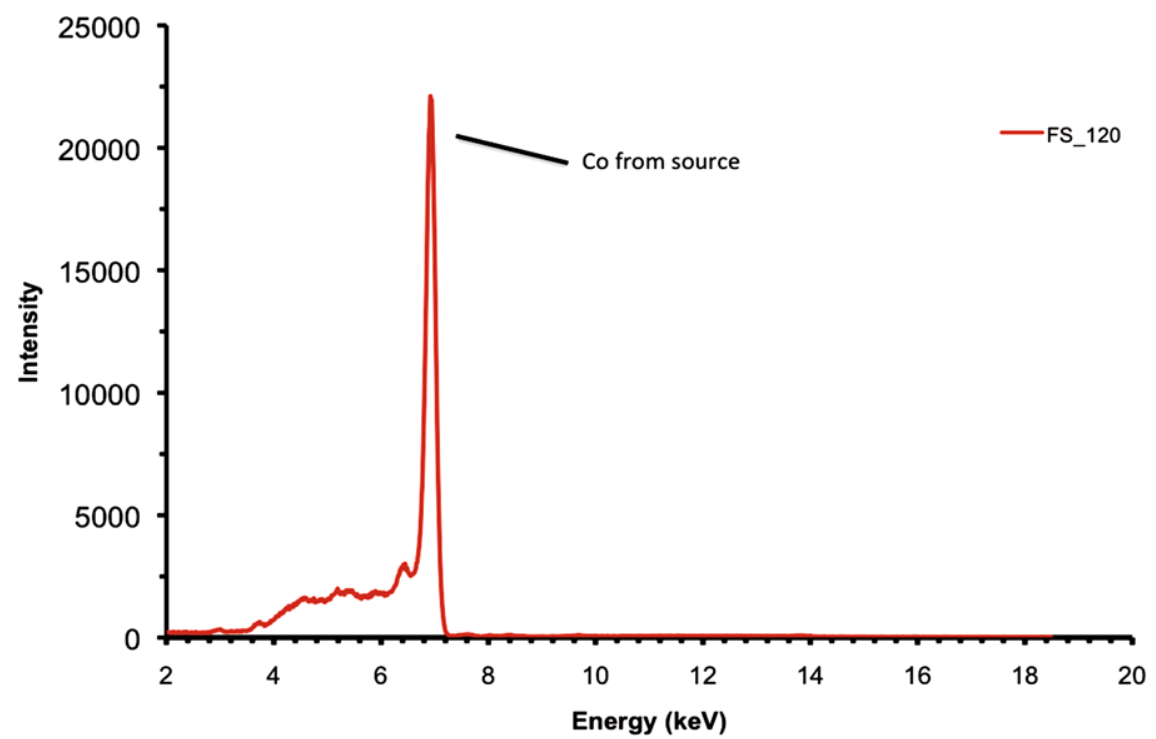

Fig. 3 X-ray fluorescence data confirming the composition of the FS120. Measurements acquired on the XSitu Terra. The cobalt peak is from the source X-ray tube. While FS-120 may contain traces of Ca or Na they were not detectable at requirements threshold. Integration time was 5990 seconds

For this and several other reasons, the FS-120 silica (Fig. 2) was selected for the OCM matrix material. It is thermally stable over the range of diurnal and seasonal temperature predicted for Gale Crater (Vasavada et al. 2012). It is virtually pure $\mathrm{SiO}_{2}$ and the elements to be avoided: $\mathrm{Ni}, \mathrm{Zn}, \mathrm{Cr}, \mathrm{K}, \mathrm{Y}, \mathrm{Sr}$ were all beneath the required thresholds or absent as measured with the commercial version of the CheMin instrument, the XSitu Terra ${ }^{\mathrm{TM}}$ (Fig. 3). The FS-120 material is manufactured as a porous cylindrical brick, and can be obtained with a range of porosities. Because the OCM application required doping of the bricks with fluorinated hydrocarbon markers, the highest porosity, $\sim$ thirty-six percent, was desirable to provide maximal surface area $\left(\sim 10 \mathrm{~m}^{2} / \mathrm{g}\right)$ for contact with the fluorinated marker. The pores are interconnected, which was verified early on by a dye test in which cylinders $(76.74 \times$ $57.5 \mathrm{~mm}$ ) were halved on the long axis and placed in a dish of dye. The entire half cylinder was saturated with the dye in about fifteen minutes. 
Table 2 Data sheet FS120 fused silica

\begin{tabular}{ll}
\hline Composition & $\mathrm{SiO}_{2}$ and $<0.5 \% \mathrm{NaO}$ \\
\hline Crystallinity & $\begin{array}{l}\text { Amorphous, although during sintering, trace amounts of cristobalite can be formed } \\
\text { at } 1100{ }^{\circ} \mathrm{C}\end{array}$ \\
Organics & None \\
Metals & None \\
Grain size & Silica granules ranging from $10-500$ microns and sintered \\
Density & $1400 \mathrm{~kg} / \mathrm{m}^{3}$ \\
Porosity & $36 \%$ \\
Surface area & $10 \mathrm{~m}^{2} / \mathrm{g}($ estimated) \\
CTE & $6-8 \times 10^{-7}{ }^{\circ} \mathrm{C}-1$ \\
Compressive strength & $10-15 \mathrm{MPa}(\mathrm{estimated})$ \\
Thermal stability & Stable to $1500^{\circ} \mathrm{C}$, although above $1000^{\circ} \mathrm{C}$, cristobalite may form \\
\hline
\end{tabular}

The FS-120 compressive strength at thirty-six percent porosity is about $12 \mathrm{MPa}$, making it well within the required limit of $230 \mathrm{MPa}$. The properties of the FS-120 porous fused silica are summarized in Table 2.

\subsection{FS-120 Testing}

The powder XRD characterization and the dye test were used to narrow the field of candidate materials. Once selected, the FS-120 was further tested to verify its suitability as the matrix for the OCM. In addition to its compressibility, the behavior of the material upon drilling with the MSL drill was an important characterization. The material was drilled with a commercial rotary-percussive drill, and it was determined that the FS-120 would yield a distribution of powdered grain sizes that is dependent upon the ratio of percussion to rotation. The rotation-only mode was an important benchmark of the potential grain size distribution during early development of the OCM because of uncertainties associated with the behavior of the ceramic material, the yet to be designed canister and the position of the OCM on the rover. The units are affixed to the front panel of the rover (Fig. 4). However, subsequent testing of the FS-120 material, design and testing of the foil lid on the containment canisters, and load testing of the rover front panel interface indicated that percussive drilling of the OCM could be achieved without concern. The distribution of powder grain sizes achieved by drilling an FS-120 cylinder using a $13 \mathrm{~mm}$ drill bit with a weight on bit of $73 \mathrm{~N}$ at a rotation speed of $250 \mathrm{RPM}$ was $9.4 \%<50 \mu \mathrm{m}, 41 \% 50-150 \mu \mathrm{m}$ and $49.6 \%>49.6 \mu \mathrm{m}$. The flexibility to achieve an appropriate grain size distribution with and without percussion is an advantage in minimizing wear on the drill bit during the mission.

This is meaningful because the SA-SPaH portioning apparatus sieves the samples delivered to SAM and CheMin to exclude grains $>150 \mu \mathrm{m}$, and the FS-120 will produce enough grains of sufficient size to deliver more than enough $<150 \mu \mathrm{m}$ sample portions. At the time this manuscript was in preparation, optimization of the MSL testbed model of the CHIMRA is ongoing and the behavior of in the OCM material during drilling and portioning will be better characterized. 
A

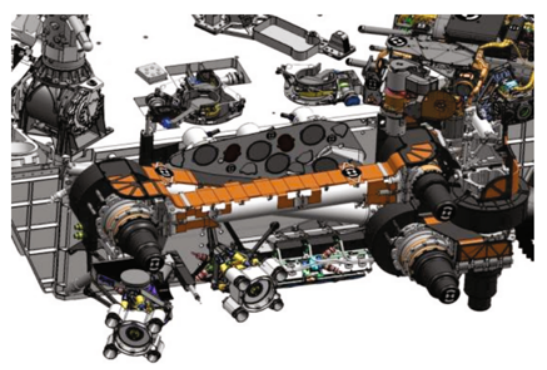

B

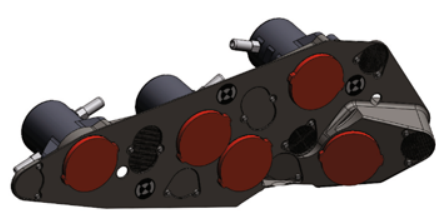

Fig. 4 Panel A illustrates the position of the OCM mounting plate that secures the units to the front of the rover. Panel $\mathbf{B}$ is a drawing of the mounting plate, showing the OCM units with their red "remove before flight" covers and the drill positioning pads between the units. Note that the top surface of the fifth unit to the far right of panel $\mathbf{B}$ is angled differently to accommodate drill positioning

\section{Organic Dopant}

A number of materials were considered as potential organic marker compounds, starting with the requirement that it be a material not found in nature. It was suggested that a perfluorinated compound might be a good candidate for the dopant, and several were considered along with fluorinated compounds that were not saturated. A list of these compounds is shown in Table 3.

The perfluorinated compounds were deemed unsuitable by virtue of their volatility, e.g., the vapor pressure was either too high or too low (Ellis et al. 2002). As a class, the perfluoroalkanes take up a large amount of spectral space. They have a large number of mass spectral peaks, which could obscure potential contaminants. Some compounds adsorb too poorly with the surface of the bricks to be good dopants, and this poor adsorption also affects the ability to retain and separate the peaks in a gas chromatogram as illustrated in Fig. 5.

The best fit for the requirements was a combination of 3 -fluorophenanthrene ( $3 \mathrm{FP}$ ) and 1-fluoronaphthalene (1 FN). Their structures are:

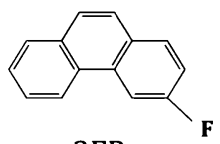

3FP

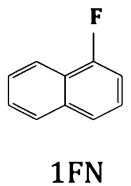

$1 F N$

3 FP has an estimated vapor pressure of $1.2 \times 10^{-4}$ Torr. The $1 \mathrm{FN}$ is more volatile with a measured vapor pressure of $1.0 \times 10^{-3}$ Torr. $3 \mathrm{FP}$ is a solid at $25{ }^{\circ} \mathrm{C}, 1 \mathrm{~atm}$, whereas $1 \mathrm{FN}$ is a liquid. These properties had an advantage of enabling us to dissolve the $3 \mathrm{FP}$ into the $1 \mathrm{FN}$, eliminating the need for additional solvents and thus minimizing the potential paths for contamination into the bricks. Also, they could be easily vaporized upon heating, requiring a minimal volume for distribution throughout the pore spaces and surface of the bricks.

In general, polycyclic aromatics adsorbed on surfaces are photo reactive in the presence of reactive oxidizing gases. However, the OCM material is hermetically sealed in a metal can until it is sampled, and minimal environmental exposure. During acquisition of the OCM sample, hardware presents a tortuous path which is likewise not going to expose the OCM 
Table 3 Candidate fluorocarbon marker compounds

\begin{tabular}{|c|c|c|c|c|c|c|}
\hline Name & Formula & $\begin{array}{l}\text { Boiling } \\
\text { point } \\
\left({ }^{\circ} \mathrm{C}\right)\end{array}$ & $\begin{array}{l}\text { Vapor } \\
\text { pressure } \\
\text { (Torr) }\end{array}$ & $\begin{array}{l}\text { Vapor } \\
\text { pressure } \\
(\mathrm{Pa})\end{array}$ & Ref. & Comments \\
\hline n-perfluorononane & $\mathrm{C}_{9} \mathrm{~F}_{20}$ & 125 & $\begin{array}{l}11.7 \times 10^{0}- \\
16.5 \times 10^{0}\end{array}$ & $1.6 \times 10^{3}$ & 3(a) & $\begin{array}{l}\text { Poor interaction,* } \\
\text { too volatile }\end{array}$ \\
\hline n-perfluorodecalin & $\mathrm{C}_{11} \mathrm{~F}_{20}$ & 141 & $\begin{array}{l}6.8 \times 10^{0}- \\
7.3 \times 10^{0}\end{array}$ & $\begin{array}{l}9.1 \times 10^{2}- \\
9.7 \times 10^{2}\end{array}$ & $\begin{array}{l}2,3(a), \\
3(b)\end{array}$ & $\begin{array}{l}\text { Poor interaction, } * \\
\text { too volatile }\end{array}$ \\
\hline perfluorotributylamine & $\mathrm{C}_{12} \mathrm{~F}_{27} \mathrm{~N}$ & 178 & $1.32 \times 10^{0}$ & $1.8 \times 10^{2}$ & 1 & $\begin{array}{l}\text { Poor interaction,* } \\
\text { too volatile }\end{array}$ \\
\hline n-perfluorotridecane & $\mathrm{C}_{13} \mathrm{~F}_{28}$ & $\begin{array}{l}193- \\
196\end{array}$ & $2.8 \times 10^{-1}$ & $3.7 \times 10^{1}$ & 3(a) & $\begin{array}{l}\text { Poor interaction, } * \\
\text { too volatile }\end{array}$ \\
\hline $\begin{array}{l}\text { n-perfluoro- } \\
\text { pentadecane }\end{array}$ & $\mathrm{C}_{15} \mathrm{~F}_{32}$ & 228 & $4.4 \times 10^{-2}$ & $5.9 \times 10^{0}$ & 3(a) & $\begin{array}{l}\text { Poor interaction,* } \\
\text { too volatile }\end{array}$ \\
\hline n-perfluoroeicosane & $\mathrm{C}_{20} \mathrm{~F}_{42}$ & 320 & 0 & - & 3(a) & $\begin{array}{l}\text { Poor interaction, }{ }^{*} \\
\text { excessive carryover }\end{array}$ \\
\hline decafluorobiphenyl & $\mathrm{C}_{12} \mathrm{~F}_{10}$ & 206 & $\begin{array}{l}9.8 \times 10^{-2}- \\
3.5 \times 10^{-1}\end{array}$ & $\begin{array}{l}1.3 \times 10^{1-} \\
4.7 \times 10^{1}\end{array}$ & $\begin{array}{l}2,3(a) \\
3(b)\end{array}$ & $\begin{array}{l}\text { Poorly retained, } \\
\text { too volatile }\end{array}$ \\
\hline 2,2'-difluorobiphenyl & $\mathrm{C}_{12} \mathrm{H}_{8} \mathrm{~F}_{2}$ & $\begin{array}{l}245- \\
265^{*}\end{array}$ & $\begin{array}{l}9.8 \times 10^{-3}- \\
4.6 \times 10^{-2}\end{array}$ & $\begin{array}{l}1.3 \times 10^{0}- \\
6.1 \times 10^{0}\end{array}$ & $\begin{array}{l}3(\mathrm{a}) \\
3(\mathrm{~b})\end{array}$ & Well retained \\
\hline 1-fluoronaphthalene & $\mathrm{C}_{10} \mathrm{H}_{7} \mathrm{~F}$ & 215 & $2.2 \times 10^{-1}$ & $2.9 \times 10^{1}$ & 1 & $\begin{array}{l}\text { Well retained, } \\
\text { too volatile }\end{array}$ \\
\hline 4-fluorobiphenyl & $\mathrm{C}_{12} \mathrm{H}_{9} \mathrm{~F}$ & 310 & $\begin{array}{l}7.8 \times 10^{-3}- \\
3 \times 10^{-2}\end{array}$ & $\begin{array}{l}1.0 \times 10^{0}- \\
4.0 \times 10^{0}\end{array}$ & $\begin{array}{l}2,3(a) \\
3(b)\end{array}$ & Well retained \\
\hline 3-fluorophenanthrene & $\mathrm{C}_{14} \mathrm{H}_{9} \mathrm{~F}$ & $\begin{array}{l}324- \\
341^{*}\end{array}$ & $1.5 \times 10^{-4}$ & $2.0 \times 10^{-2}$ & $3 b$ & Well retained \\
\hline 1-fluoropyrene & $\mathrm{C}_{16} \mathrm{H}_{9} \mathrm{~F}$ & $\begin{array}{l}369- \\
376^{*}\end{array}$ & $4.9 \times 10^{-6}$ & $6.5 \times 10^{-4}$ & $3 b$ & Well retained \\
\hline 3-fluorochrysene & $\mathrm{C}_{18} \mathrm{H}_{11} \mathrm{~F}$ & $\begin{array}{l}396- \\
440^{*}\end{array}$ & $7.1 \times 10^{-7}$ & $9.4 \times 10^{-5}$ & $3 b$ & Well retained \\
\hline $\begin{array}{l}\text { 9-fluorobenzo[k]- } \\
\text { fluoranthrene }\end{array}$ & $\mathrm{C}_{20} \mathrm{H}_{11} \mathrm{~F}$ & $\begin{array}{l}394- \\
470^{*}\end{array}$ & $7.1 \times 10^{-7}$ & $9.4 \times 10^{-5}$ & $3 b$ & Well retained \\
\hline
\end{tabular}

Data source for vapor pressure at $25^{\circ} \mathrm{C}: 1$, http://www.sigmaaldrich.com; 2, http://www.wolframalpha.com/ entities/chemical_vapor_pressures (calculated prediction); 3, http://www.chemspider.com (modeled prediction using (a) ACD Lab's ACD/PhysChem Suite and (b) EPA's EPIsuite); 4, http://www.chemyuhao.com. * Poor interaction with GC column stationary phase is due to limited polarizability. This limitation results in the materials being poorly retained in the GC or on the OCM surface. Having a well-resolved GC chromatographic peak is necessary to assure that the OCM could be readily measured and distinguished from potential martian compounds of interest

sample to light. The radiation stability of polycyclic aromatics is quite robust, and every other moiety on the polycyclic aromatic hydrocarbon, e.g., hydrogen, is more likely to be emitted from the molecule before the fluorine, based upon the $70 \mathrm{eV}$ beta radiation used to ionize the species in a mass spectrometer. Other inelastic collisions due to particle radiation will have similar results in the gas phase, and energy transfer to the surfaces to which the molecules are adhered will dominate the energetic decay of the radiation interactions in the aromatic hydrocarbons, like the relaxation of excited state toluene in air and low vacuum, which is dependent only upon intermolecular collision rates. These are strong reasons for selection of fluorinated polycyclic aromatics for the OCM application: their radiation stability, their unique ionization properties, their long-term molecular stability and chromatographic 


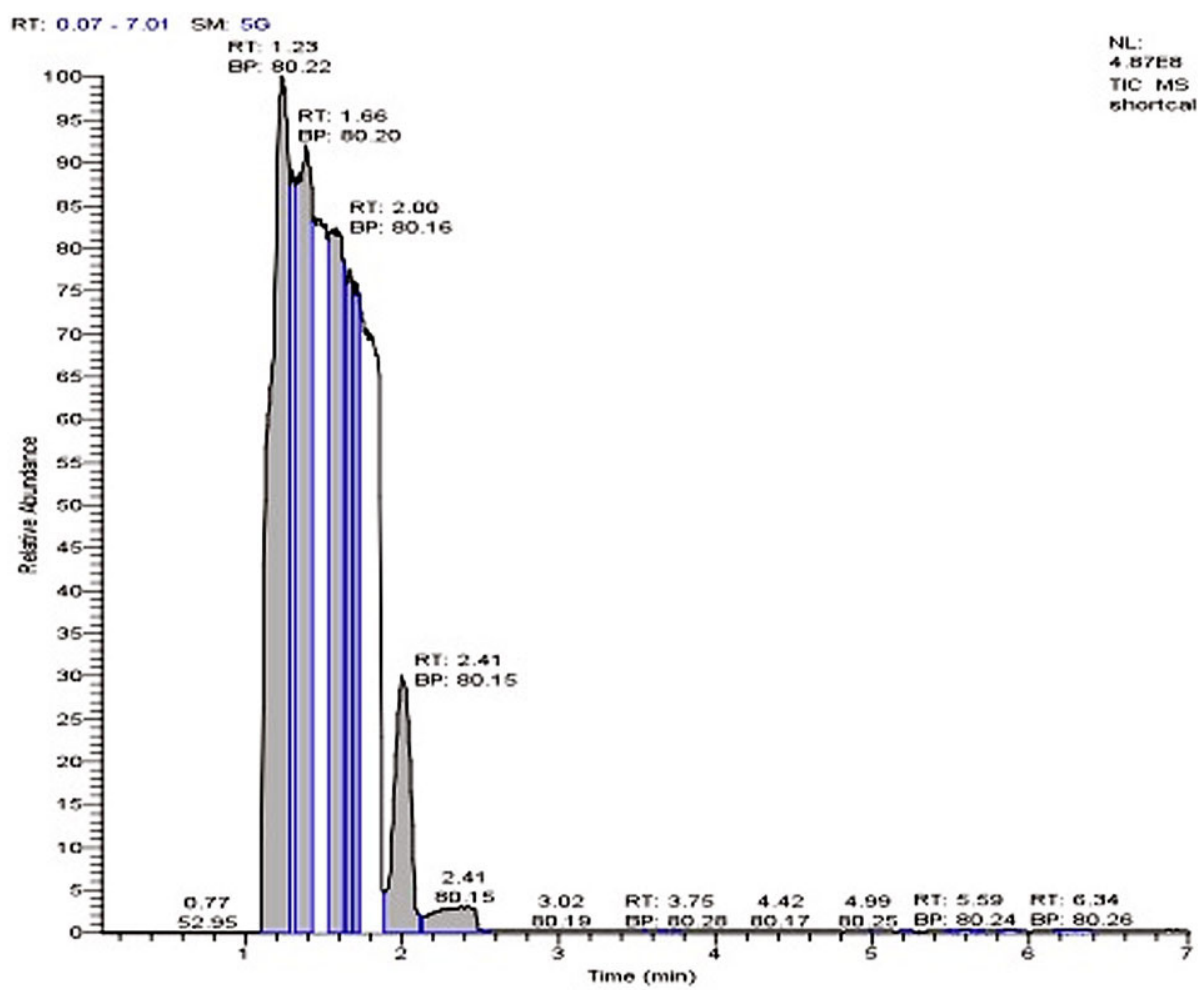

Fig. 5 GC/MS Chromatogram (split injection) of the poorly retained perfluoroalkanes. The retention time is effectively the dead time of the column plus the tailing of the peak due to overloading of the column. This is caused by near zero capacity factors on the $5 \%$ phenyl methyl silicone equivalent GC column $(25 \mathrm{~m} \times 0.22 \mathrm{~mm}$ id $\times 0.1$ micron SGE HT-5). The GC peaks for these compounds in diluted samples were beneath the solvent peak and thus not detected

properties. The radiation dose at the surface of Mars is below the level that degradation of the material to any significant extent can be expected.

\section{OCM Containment System}

The requirements for the OCM could not be met without some type of containment to protect its cleanliness and prevent potential loss of the marker. Several engineering constraints were placed upon the containment system to avoid risk to the SA-SPaH as well. One such constraint was to avoid adding more actuators and associated heaters as would be needed for a motorized cover. Another was to avoid having the drill pierce through metal, either by drilling or puncturing, although this latter constraint was ultimately relaxed after testing demonstrated minimal risk. Other requirements for containment included individually sealed OCM canisters (to maintain cleanliness). Individual, single-use canisters minimize the potential for contamination from use to use. The hermetic seals had to be maintained with a leak rate no greater than $10^{-9}$ atm- $\mathrm{cm}^{3} \mathrm{~s}^{-1} \mathrm{He}$ with canister pressure lower than Mars atmosphere shown by test and analysis, and there needed to be some means of verifying the 
seal integrity on ground. Access ports for doping the bricks with the fluorocarbon markers were required as well, and these would also be verifiably sealed.

The dimensions of the OCM bricks (and hence the containment canisters) were driven by (a) a need to accommodate the depth to which martian rocks were to be drilled $-4 \mathrm{~cm}$ plus some margin to avoid drilling through the entire brick and hitting the bottom of the can, and (b) the lateral accommodation of up to $13 \mathrm{~mm}$ radial two degree angular drill misalignment. The reason for the depth requirement to match the sampling depth of the martian samples was to ensure that the entire length of the drill bit that touches rock be verified for cleanliness.

Canister components and assembly procedures were required to be sufficiently clean to guarantee that the collected sample be free from organic contamination greater than $36 \mathrm{PPB}$ and this number had to be verifiable.

The OCM bricks had to be immobilized within the cans so that they would not rotate along with the drill, and the canister units had to be secured and protected against all loads, including preloading and drilling, and they had to be accessible to the drill, so the front panel of the rover was selected as the mounting site for the OCM assembly. There was insufficient space to accommodate more than five canisters, so the original recommendation of six to eight units could not be met.

\subsection{Canisters}

Various containment strategies were considered. A single large box with motorized cover holding several OCM samples was dismissed because (a) after first use, all subsequent samples would have successively been exposed to more opportunities for contaminations, (b) the use of a motorized lid would not only have required yet another actuator and heater, but the requirements for its use might have limited accessibility of the OCM for thermal considerations, and (c) the single lid is, of course, a single point of failure risk. We also investigated the use of non-porous ceramic glazing with which to encapsulate each brick. This strategy also offered more risks than solutions: the physical properties of such glazes make them brittle and there is significant cracking under preload and drilling, and they also would have presented a challenge for providing access ports to the porous brick for doping with the marker compounds.

In the final design, it was agreed that individual metal canisters (6Al-4V titanium) with access ports for doping should be used and the tops sealed with a foil lid (6Al-4V Ti) secured by a laser weld to the can. An Oldham type coupling plate (for example Tsai 2001) in the bottom of the can fits into a groove machined into the bottom of the brick to prevent rotation of the OCM during drilling (Fig. 6). The bricks fit snugly in the canisters, not only onto the coupling plate, but also retained at the top surface by a wave spring and spiral retaining ring which preload the brick on the long axis through a conical clamping ring. The retention mechanism was qualified for bounding launch vibrations and pyroshock loads. There is a small headspace above the top surface of the brick, which provides clearance for torn pieces of the top seal, which is punctured by the drill, providing access to the brick for drilling.

The doping ports are based upon a design that had successfully been incorporated into the Cassini-Huygens (Niemann et al. 2002) and SAM instruments (Mahaffy et al. 2012). A gland port is machined into the canisters with threads to match a gland screw which has been welded to $\mathrm{Ni} 1 / 8^{\prime \prime}$ tubing. This gland screw assembly is seated against a platinum O-ring (Fig. 7). The Ni tube can then be mated with a Swagelok valve for introduction of the dopants. After the bricks have undergone the doping process, the tubes are pinched off and covered with $\mathrm{Al}$ protectors that are screwed into place to prevent jarring of the port seal 
A

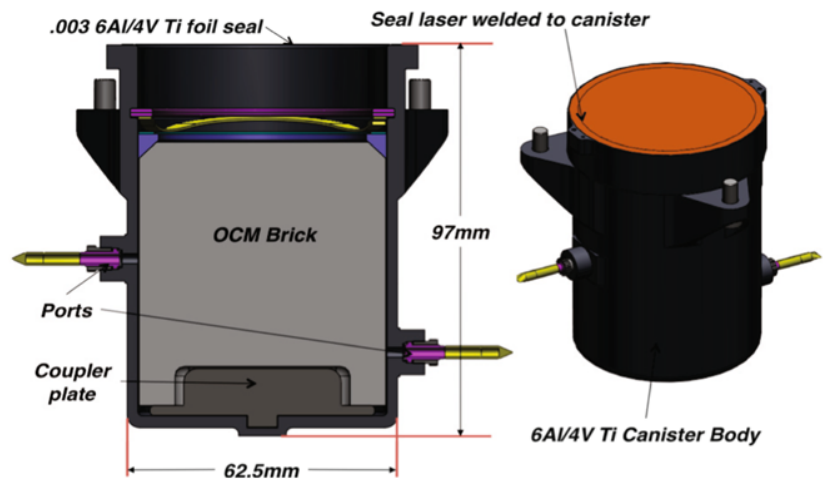

C

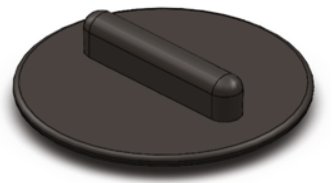

Fig. 6 The OCM containment canister. Panel A: Each brick is individually contained in a titanium canister that has an inlet and outlet port for the introduction of dopant and evacuation to roughly $10^{-5}$ Torr. Note that there is a head space above the brick to accommodate puncture an associated tearing of the foil lid prior to drilling. This ensures that there will not be metal tailings from the lid in the brick whilst drilling. The three flanges (only two are shown is panel $\mathbf{A}$ ) enable fastening of the canister to the mounting plate. Panel B: The welded foil lid is shown in addition to the mounting flanges. Note that the ports are positioned on opposite sides of the canister to both assist in the distribution of the dopant during injection and to accommodate the positioning of the canisters in the mounting plate. Panel $\mathbf{C}$ : The coupling plate fits into the bottom of the canister, which is grooved to accommodate it, and also into the brick, which is also grooved and fits snugly onto the coupler

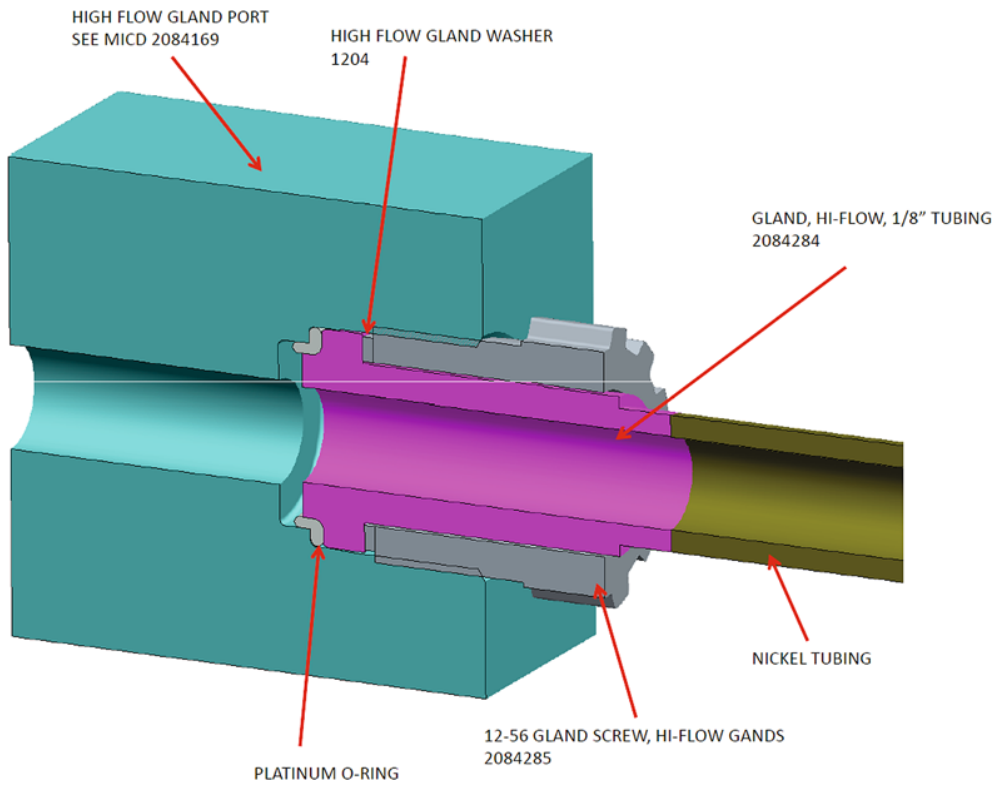

Fig. 7 This is a drawing of the gland/port assembly. The high flow $1 / 8^{\prime \prime}$ tube is welded to nickel tubing and held in place against a platinum O-ring by a 12-56 gland screw, which is torqued into the port of the canister 
and potential loss of vacuum. The vacuum is drawn to prevent a positive pressure relative to Mars ambient. The port pinch-off tubes were qualified in a bounding launch vibration load test and 8 proto-flight-level thermal cycles.

The five canisters are held in place on the front of Curiosity by a mounting plate, also constructed of the $6 \mathrm{Al}-4 \mathrm{~V} \mathrm{Ti}$ (Fig. 4). The foil surfaces of the can lids are flush with the surface of the mounting plate, and the cans are mounted by screwing them to the rear of the plate with the mounting flanges on the cans as shown in Fig. 6b. The front surface of the plate also includes prong contact pads for the drill sensors against which the preload is applied for puncture of the lid and for drilling (Fig. 4b).

\section{Preparation of Flight Units}

\subsection{FS-120 Bricks}

The OCM cylinders were verified to be within size tolerances at the time of manufacture at HP Technical Ceramics, Ltd in Sheffield $(65+0.5 /-0 \mathrm{~mm} \times 57+0.1 /-0.2 \mathrm{~mm})$. At JPL, the bricks were subsequently machined so that the top rim was chamfered and an alignment slot created in the base into which the coupling plate would secure the brick against rotation (Fig. 2).

The bricks were baked at $550{ }^{\circ} \mathrm{C}$ for four hours under gentle flow of Earth atmospheric gas to combust any residual material. While fused silica will tolerate a higher temperature bakeout to $1000{ }^{\circ} \mathrm{C}$ without risking the formation of cristobalite (high temperature $\mathrm{SiO}_{2}$ crystals), it is important not to dehydrate the silica too much, which diminishes its capability to adsorb the dopant fluorocarbon markers. Cleaned bricks were then wrapped in double sheets of baked ultra high vacuum foil until installation into the containment canisters.

\subsection{Encapsulation Hardware}

All hardware components were precision cleaned by a multi-step procedure. Note that all solvents were HPLC grade to minimize the potential for contamination by traces of other compounds. First the parts were immersed in a clean beaker of HPLC grade acetone and sonicated for 2 to 5 minutes. Then they were immersed in HPLC grade hexanes under sonication for another 2 to 5 minutes. A third sonication in HPLC grade isopropyl alcohol (IPA) for 2 to 5 minutes followed this step. A final rinse was then performed on a class 100 laminar flow bench using HPLC grade hexanes, wetting all hardware surfaces. The rinse solvent was collected in a cleaned vessel and labeled for later verification analysis. The cleaning procedure was completed by forcing the hardware dry with ultra high purity $\mathrm{N}_{2}$ gas.

\subsection{Fluorocarbon Marker Compounds}

The fundamental requirement for the marker compound was that it be detectable by SAM, so we targeted nanomolar concentrations that are readily detectable by SAM (Table 6). Preliminary experiments concluded that the minimum $1 \mathrm{FN} / 3 \mathrm{FP}$ ratio that could be achieved was $2.046 \mu \mathrm{L} / \mathrm{mg}(4.437 \mathrm{nmol} / \mathrm{nmol})$. The nominal expected sample size to be delivered to SAM is $0.05 \mathrm{~cm}^{3}$ of $<150 \mu \mathrm{m}$ powdered FS-120 brick. To achieve 10-nmol detections in a 0.05 $\mathrm{cm}^{3}$ sample volume, $2.3 \mu \mathrm{L}$ of $1 \mathrm{FN}$ and $4.14 \mathrm{mg}$ of $3 \mathrm{FP}$ per single brick are needed; giving a $1 \mathrm{FN} / 3 \mathrm{FP}$ ratio is 0.56 (Tables 4 and 5). This ratio is $\sim 4$ times less than the achievable minimum ratio determined experimentally. Thus, the experimental minimal $1 \mathrm{FN} / 3 \mathrm{FP}$ ratio was applied in making the dopant solution. Furthermore, a target concentration of 10-nmol 3 FP was chosen since larger quantities of $1 \mathrm{FN}$ may make up for the expected evaporative loss of $1 \mathrm{FN}$ once exposed to 10-mbar atmospheric conditions on Mars. 
Table 4 Variables used in calculations

\begin{tabular}{ll}
\hline Variables & Values \\
\hline Total brick volume minus pores & $105.45 \mathrm{~cm}^{3}$ \\
Total brick volume including pores & $165.86 \mathrm{~cm}^{3}$ \\
1 FN atomic mass & $146.17 \mathrm{~g} / \mathrm{mol}$ \\
1 FN density & $1.330 \mathrm{~g} / \mathrm{ml}$ \\
3 FP atomic mass & $196.1 \mathrm{~g} / \mathrm{mol}$ \\
\hline
\end{tabular}

Table 5 Calculations for determining the amount of dopants needed per brick

\begin{tabular}{lll}
\hline Eq. & Calculation & Result \\
\hline 1 & $10 \mathrm{nmol} / 0.05 \mathrm{~cm}^{3}$ brick $\times 10^{-9} \mathrm{~mol} / \mathrm{nmol} \times 105.45 \mathrm{~cm}^{3}$ brick $=$ & $\begin{array}{l}2.11 \times 10^{-5} \text { mol of } \\
\text { each dopant per brick }\end{array}$ \\
2 & $\left(2.11 \times 10^{-5} \mathrm{~mol} 1 \mathrm{FN} \times 146.17 \mathrm{~g} / \mathrm{mol} \times 1000 \mu \mathrm{ml}\right) / 1.330 \mathrm{~g} / \mathrm{ml}=$ & $2.3 \mu \mathrm{l} \mathrm{FN} \mathrm{per} \mathrm{brick}$ \\
3 & $2.11 \times 10^{-5} \mathrm{~mol} 3 \mathrm{FP} \times 196.1 \mathrm{~g} / \mathrm{mol} \times 1000 \mathrm{mg} / \mathrm{g}=$ & $4.14 \mathrm{mg} 3 \mathrm{FP}$ per brick \\
4 & Ratio $1 \mathrm{FN} / 3 \mathrm{FP}(\mu \mathrm{l} / \mathrm{mg})=$ & 0.56 \\
\hline
\end{tabular}

Table 6 Target verses actual amounts of dopants per brick

\begin{tabular}{lll}
\hline Variable & Target & Actual $^{\S}$ \\
\hline Number of bricks $^{*}$ & 17 & 15 \\
Amount of 3 FP in dopant solution $^{* * *}$ & $70.33 \mathrm{mg}$ & $60.90 \mathrm{mg}^{* *}$ \\
Amount of 1 FN in dopant solution $^{* *}$ & $144 \mu \mathrm{l}$ & $170 \mu \mathrm{l}$ \\
Amount of 3 FP per brick & $4.14 \mathrm{mg}$ & $3.58 \mathrm{mg}$ \\
Amount of 1 FN per brick & $8 \mu \mathrm{l}$ & $10 \mu \mathrm{l}$ \\
Amount of 3 FP expected per $0.05 \mathrm{~cm}^{3}$ brick & $10 \mathrm{nmol}$ & $8.65 \mathrm{nmol}(5.50 \mathrm{nmol})$ \\
Amount of 1 FN expected per $0.05 \mathrm{~cm}^{3}$ brick & $27.2 \mathrm{nmol}$ & $26.0 \mathrm{nmol}(16.5 \mathrm{nmol})$ \\
\hline
\end{tabular}

$\S$ Predicted amounts of dopants based on the actual dopant solution are dependent of brick volume with or without (in parentheses) pore spaces taken into consideration

* Although there were only 15 bricks to dope, additional dopant solution was prepared in case it was needed

** 3 FP is sticky and clingy, making it difficult to weigh. Only $60.9 \mathrm{mg}$ of the available dopant was successfully transferred to the vial on the microbalance

*** The amount of $1 \mathrm{FN}$ was adjusted to a volume easily measured and injected into the doping manifold using a $10-\mu l$ syringe

\subsection{Assembly and Doping of OCM Units}

\subsubsection{Hardware and Bricks}

After the bricks, canisters, doping port/gland assemblies and brick retention hardware were cleaned, the OCM units were assembled in a class 1000 clean room at the Jet Propulsion Laboratory. All personnel donned full clean-room garb: "bunny suits", masks and double gloves. Work surfaces were covered with clean sheets of ultra high vacuum (UHV) foil for each assembly.

The flow of canister assembly was designed to minimize the chance of contamination and units were fully assembled one at a time. First, the doping ports were installed and their 
leak-tight seal checked with a helium leak detector. Because the seals were tested prior to installation of the bricks and welded foil lids, a special leak-test cover and viton O-ring were used and the actual gland port assemblies closed off at the distal ends of the nickel tubes by the Swagelok valves. All hardware was handled with precision-cleaned tools (cleaned by the multi-step process described in Sect. 6.2). Following successful installation of the doping ports (two per can as shown in Fig. 6) The coupling plate was installed in the bottom of the can, then the brick, by peeling away one layer of foil and grasping the brick by the remaining layer whilst lowering it into the can and pressing it onto the coupling plate. The retaining hardware was then installed by pressing the conical face of a clamp ring over the chamfered edge of the brick and then a wave spring and spiral retaining ring. Shims were employed beneath the wave spring to maintain a consistent spring height, and shim thickness recorded for each unit.

The units were then ready for closure with the welded lid. The welding procedure included a custom fixture on a rotational stage. The foil disks were positioned using the welder operated by the laser-welding technician. Helium flow was established for five minutes prior to the welding operation, and then the welding was executed. Following the welding procedure, a helium leak test was conducted by using one of the Swagelok valves on the gland ports to establish test pressure on the leak tester, and then flowing helium at the weld site. If the leak rate was less than $1 \times 10^{-9}$ atm- $\mathrm{cm}^{3} \mathrm{~s}^{-1} \mathrm{He}$, the weld was deemed successful, and the can gently purged with nitrogen and valves closed. A protective aluminum cover was installed over the foil lid.

Once the units were assembled, they were double-wrapped in baked UHV foil, enclosed in two dry nitrogen-purged Amerstat bags and labeled for shipment. Fifteen units (five for flight, five for the SAM testbed, two flight spares, two manufacturing contingency units and one qualification unit) were hand carried to NASA Goddard Space Flight Center for the doping operations.

\subsubsection{Doping}

The OCM units were received into the ISO class 6 clean room at GSFC and visually inspected. Again all personnel were in full bunny suit, masks and double nitrile gloves. The process required construction of a special manifold for doping (Fig. 8) and execution of the process in a chemical fume hood because of the use of volatile fluoro-hydrocarbons.

The doping manifold was designed to not only enable a uniform injection process for each unit, but to minimize the potential for contamination and allow for verification of the cleanliness of the injection pathway as well as verification of the fluorocarbon marker compounds downstream of the injected canister.

The use of a large oven (Lindbergh/Blue M mechanical oven) enabled the heating of several OCM units at one time, and the oven was under gentle purge of $\mathrm{N}_{2}$ gas to prevent discoloration of the hardware. Injection of the dopant into the canisters required heating to evenly distribute the marker compounds and then cooling prior to establishing a vacuum to roughly $10^{-5}$ Torr. The concluding step was pinching off the doping ports and capping them (Fig. 9c) to minimize later risk of mechanical damage. The doping operation could only be executed on one canister at a time and the procedure is summarized as:

1. Assemble a precision-cleaned injection adaptor into doping manifold.

2. Attach a bypass tube from canister input and output manifold lines and pump down the manifold with $\mathrm{N}_{2}$, then take a residual gas analysis (RGA) measurement of manifold background. Also collect a tenax trap sample to record manifold background. Then bypass the trap. 


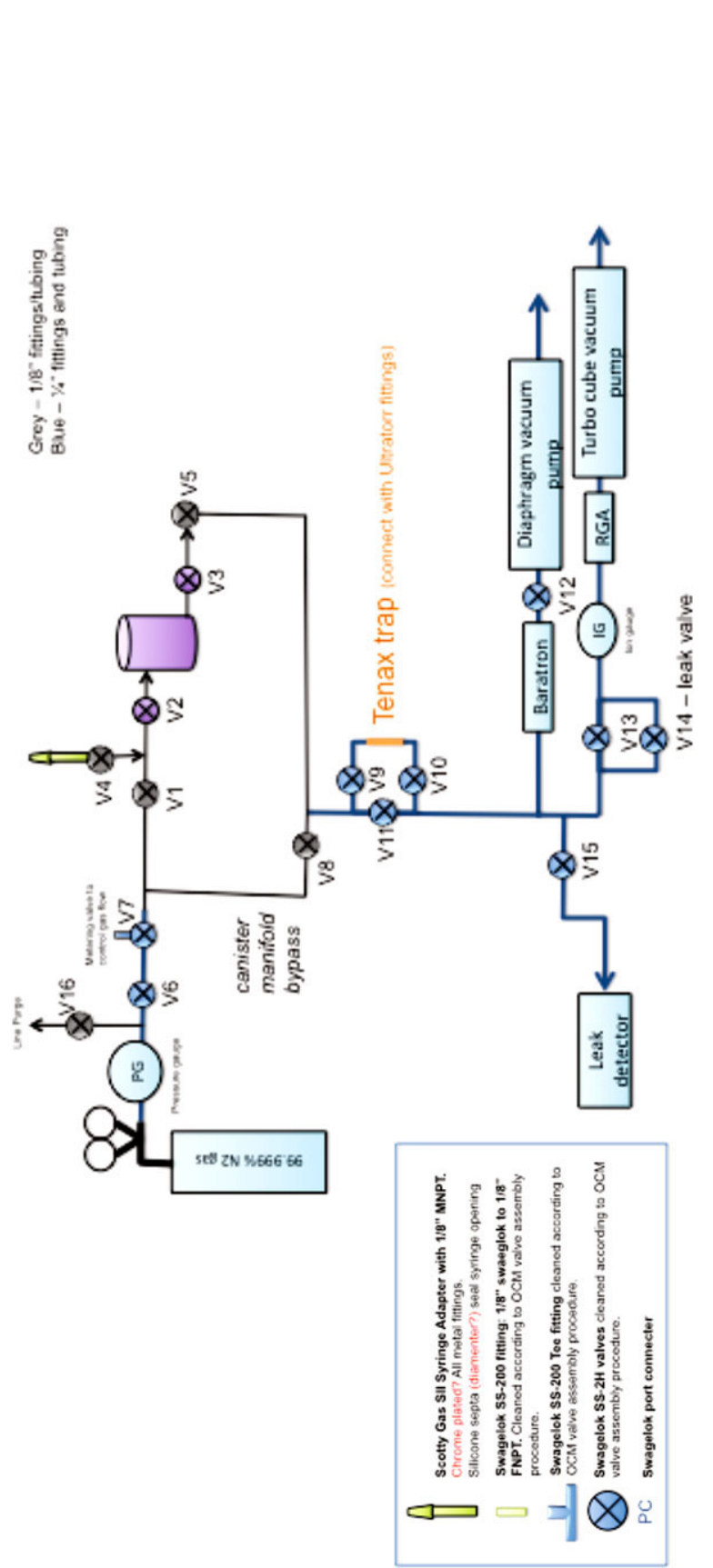

$\stackrel{\infty}{*}:=$

象语

क्ष

$\varangle$

일

卷

워ㅂㅠㅛ

范

छ छ

낭

둥ㅇㅇ

司

$\exists$ ㄷㅇㅇ

후웡

音 $\cdot \frac{\pi}{\Xi} \frac{\pi}{2}$

.

음

ज.

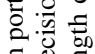

을 를

氙

$\exists$

远 $\varangle$

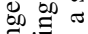

츨

过 :

.气

สี ฮี

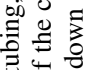

(

文:

仓े 記

穷导.

능 言雚

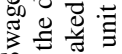

क

菏

응믕

.5.

클

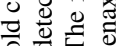

钅完

छ

on $)$

言寻

ฮี

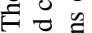

응 응

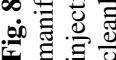


A

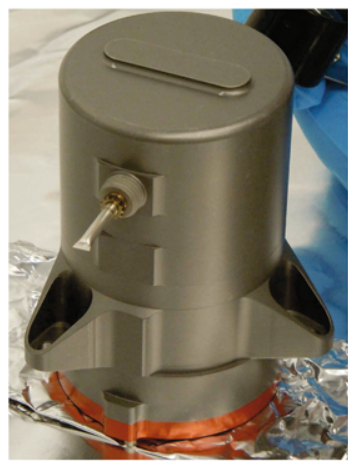

B

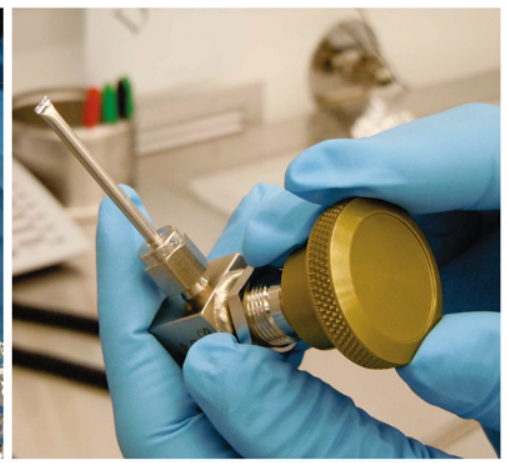

C

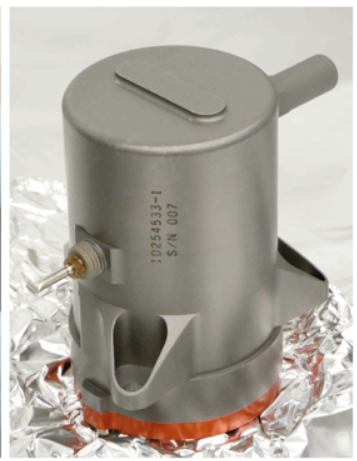

Fig. 9 The pinch-off process separates the inlet and outlet port tubes into two leak-tight halves. The pinched-off inlet is shown prior to capping in Panel $\mathbf{A}$. The other half of the pinch-off tube is still attached to the valve and shown in Panel $\mathbf{B}$, and it is this half of the tube that is leak tested to verify a satisfactory pinch-off. Panel $\mathbf{C}$ depicts one port pinched but uncapped and the other with the protective cover (right side of frame)

3. Connect the OCM unit into doping manifold (see Fig. 8) and open inlet valve.

4. Wrap the manifold with heating tape and thermocouples and heat to $\sim 75^{\circ} \mathrm{C} \pm 15^{\circ} \mathrm{C}$ to encourage migration of the dopant toward the cooler brick

5. Inject dopant through the syringe adaptor into the cans.

6. Cool until manifold temperature is down to $40{ }^{\circ} \mathrm{C}$ and remove OCM can from manifold and place in tray for baking at $250{ }^{\circ} \mathrm{C}$ for four hours.

\subsubsection{Pinch-off and Sealing of Dopant Ports}

After the cans had been doped and baked, the OCM units were pumped down until no decrease in pressure was registered for fifteen minutes - to around $10^{-5}$ Torr, and the dopant tubes were mechanically sealed by a mechanical crimp and pinch-off tool, leaving a leaktight seal on both ends of each pinched-off tube (Fig. 9a, b). The helium leak test could only be conducted on the tube end left in the Swagelok valve; the pinch-off on the canister port could not be verified by He test. However post pump-down concavity of the foil lid was measured with a tool developed for that purpose and then measured again following pinchoff of the gland/port assemblies (Fig. 10). Had there been a leak, the foil would have been deflected up to some degree, and in fact the measurements were corroborative of a good seal. It should be noted that the concavity of the seals was measured once again after delivery to JPL for installation on the rover and again after helium bomb pressurization and prior to rover close-out before launch, and the measurements were consistent with a good seal. Note that Helium "bomb" pressurization to 1.2 atm for 1 minute was performed after receiving canisters at JPL and canisters were subsequently tested for helium leaking out. This verified structural integrity of the foil seal. A qualification-level vibration test and 3 protoflightlevel thermal cycles were performed on an EM assembly with one flight-type manufacturing contingency canister and the helium bomb pressurization was repeated. A flight acceptancelevel vibration test and 3 protoflight-level thermal cycles were performed on the flight unit with only seal-deflection measurement verification to avoid overstressing the flight units.

The brick canisters were always wrapped in a layer of UHV foil during doping and heating so that handling would be minimized. 
Fig. 10 A method for verifying the vacuum of the canister was devised. The foil lid exhibits some concavity upon pumping down the can, and the degree of concavity was measuring the gap between the deflection device and the welded foil lid with a feeler gauge
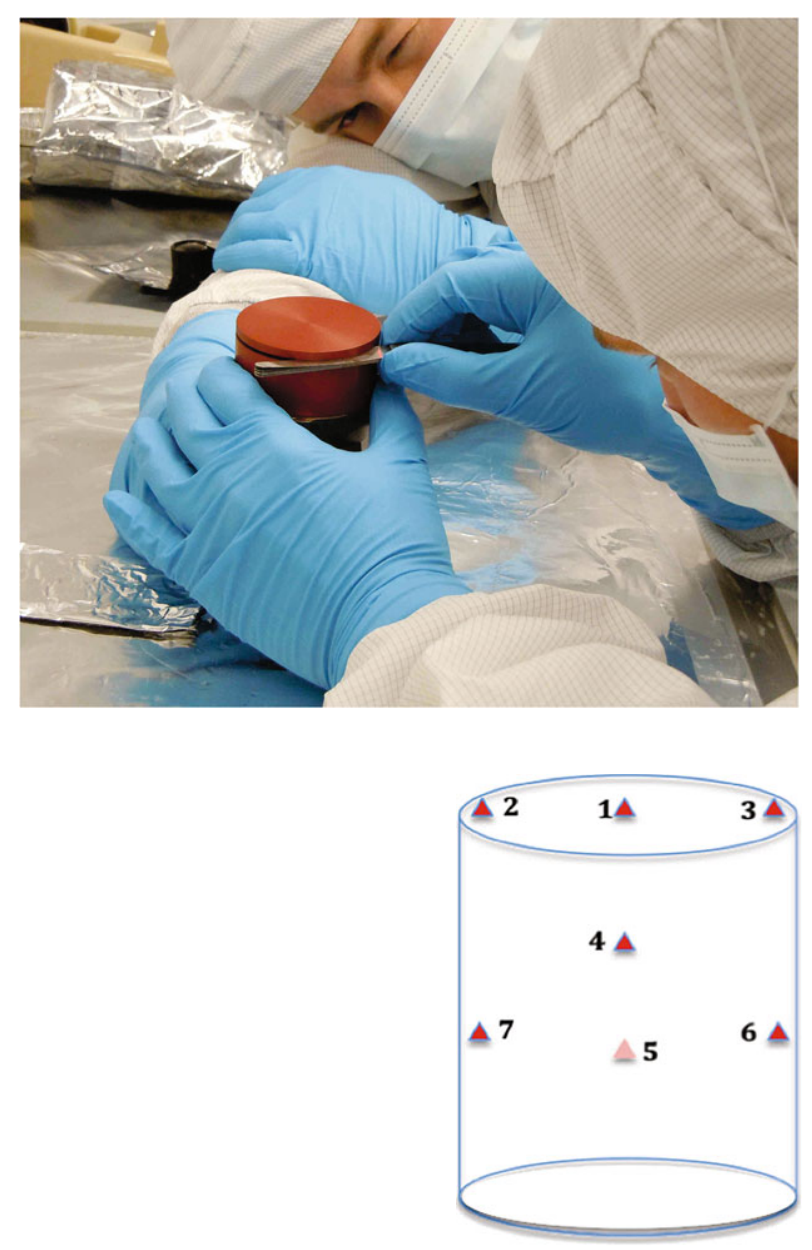

Fig. 11 The drawing illustrates the locations from which powders were gouged from a doped OCM brick to verify that the dopant had perfused the porous ceramic. Locations 1, 2 and 3 are shallow powder samples including surface, and they were acquired from roughly the same depth to check for differences radially. This is true also for samples 6 and 7. Sample locations 4 and 5 correspond roughly to the places on the brick most proximal to the doping ports

\subsection{Verification of Dopant Distribution}

The OCM verification canister was opened in the clean room fume hood where it had been doped. The foil lid was sliced with a precision cleaned blade and the brick sampled in place while it was in the canister to minimize surface area for potential contamination exposure. The locations of the verification sample collection are mapped in Fig. 11.

OCM bricks were sampled with a solvent cleaned steel ice pick and hammer and directly collected in UHV foil. About 250 milligrams of each OCM brick sample were placed in an ashed glass tube immediately upon removal from the brick. All samples were collected in duplicate. Blank material (unused FS120 brick ashed at $550{ }^{\circ} \mathrm{C}$ for 3 hours) placed in a glass tube at the same time as the other samples was interspersed in the analytical sequence.

Samples were analyzed via automated thermal desorption-gas chromatography mass spectrometry (TD-GCMS) using a Water Quattro Micro GC fitted with a Gerstel thermal desorption unit attached to a pressure-temperature volatilization (PTV) inlet (Gerstel CIS4). The Quattro Micro GC was tuned to optimize detection for $50-550 \mathrm{~m} / \mathrm{z}$ scans (on MS2) at 5000 scans/second and enhance signal to noise. Samples were thermally desorbed at $300{ }^{\circ} \mathrm{C}$ 
Table 7 FS-120 powder collected from the OCM verification brick

\begin{tabular}{|c|c|c|c|c|c|c|c|}
\hline \multirow[t]{2}{*}{ Sample } & \multirow[t]{2}{*}{$n$} & \multicolumn{3}{|c|}{$3-\mathrm{FP} \mathrm{nmol} / 0.05 \mathrm{cc}^{*}$} & \multicolumn{3}{|c|}{$1-\mathrm{FN} \mathrm{nmol} / 0.05 \mathrm{cc}^{*}$} \\
\hline & & Average & $\begin{array}{l}1 \sigma \text { standard } \\
\text { deviation }\end{array}$ & Range & Average & $\begin{array}{l}1 \sigma \text { standard } \\
\text { deviation }\end{array}$ & Range \\
\hline blank & 1 & BDL & & & BDL & & \\
\hline $12.5 \mathrm{~mm}$ depth & 2 & 0.20 & 0.11 & 0.16 & 11.2 & 13.8 & 19.5 \\
\hline $17.5 \mathrm{~mm}$ depth & 2 & 0.10 & 0.01 & 0.01 & 14.3 & 16.5 & 23.3 \\
\hline $24.5 \mathrm{~mm}$ depth & 2 & 0.14 & 0.01 & 0.01 & 18.7 & 17.7 & 25.1 \\
\hline $34.5 \mathrm{~mm}$ depth & 2 & 0.11 & 0.01 & 0.02 & 19.2 & 17.9 & 25.4 \\
\hline $41 \mathrm{~mm}$ depth & 2 & 0.11 & 0.00 & 0.01 & 21.8 & 22.6 & 32.0 \\
\hline $48 \mathrm{~mm}$ depth & 2 & 0.32 & 0.32 & 0.46 & 21.9 & 24.4 & 34.5 \\
\hline $50 \mathrm{~mm}$ depth & 2 & 0.11 & 0.03 & 0.04 & 18.9 & 19.9 & 28.1 \\
\hline spot $1^{\S}$ & 2 & 0.16 & 0.11 & 0.16 & 10.1 & 7.2 & 10.1 \\
\hline spot $2^{\S}$ & 2 & 0.12 & 0.07 & 0.09 & 14.5 & 11.4 & 16.1 \\
\hline spot $3^{\S}$ & 2 & 0.09 & 0.06 & 0.08 & 17.9 & 22.0 & 31.2 \\
\hline spot $4^{\S}$ & 2 & 0.24 & 0.01 & 0.01 & 52.2 & 53.8 & 76.1 \\
\hline
\end{tabular}

$\S_{\text {See Fig. } 11 \text { for locations on brick }}$

* Dopant concentrations are based on a calibration using FS120 doped with 3 FP

BDL-below detection limits

Fig. 12 Vertical depth profile of estimated dopant concentration through brick. Concentrations are averages for duplicates (see Table 7)

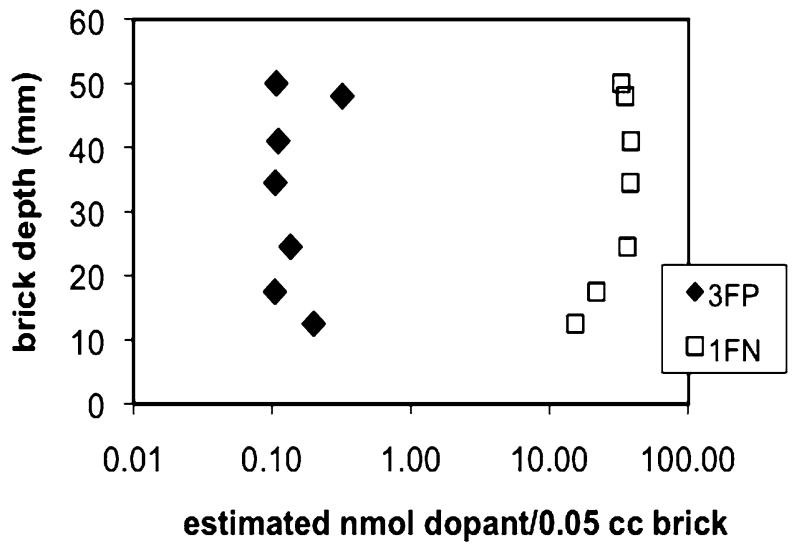

for 3 minutes and condensed in the inlet at $50{ }^{\circ} \mathrm{C}$ before being transferred to the column at $300{ }^{\circ} \mathrm{C}$. The analytes were separated on a RTX-5ms column (30 meter length, $250 \mathrm{mi}-$ crometer i.d., 25 micrometer film thickness) that was held for $1 \mathrm{~min}$ at $50{ }^{\circ} \mathrm{C}$ then ramped at $6{ }^{\circ} \mathrm{C} /$ minute to $320{ }^{\circ} \mathrm{C}$. Dopants were detected based on matching $\mathrm{GC}$ retention time and mass spectra of the original dopant solution.

The results of the doping verification showed that both 3 FP and 1 FN were detectable in all samples from the brick and absent from the blanks (Table 7 and Fig. 12). The more mobile $1 \mathrm{FN}$ was present at a higher concentration, as was expected. The SAM flight instrument is even more sensitive than the benchtop GCMS used to verify that the dopants perfused the OCM brick (see Mahaffy et al. 2012, this issue), which provides confidence that the marker compounds will be detectable by SAM on Mars. Note that access to the brick was 
not flight like, however there are verification canisters remaining at the JPL test bed for future verification with the SA-SPaH test unit.

\section{Summary}

The MSL Organic Check Material units are a limited resource on the Curiosity rover. The retention of five identical units at the SAM test bed provides an opportunity to investigate hypothetical interactions of martian materials or potential contaminants with the OCM in an analogue investigation. The accommodation of multiple units allows operational flexibility throughout the length of the mission. The approach to the fabrication and containment of this external standard is a new capability in extraterrestrial chemical characterization and will support the interpretation of such experiments as Curiosity enables our robotic exploration of Gale Crater.

Acknowledgements At JPL: Thanks to William Abbey for technical assistance in evaluation of ceramic materials, and Andrew Etters for early conceptual work on the encapsulation. James Pura provided technical assistance during the machining of the bricks, and Mark Anderson conducted the cleanliness analysis. John Bousman provided patience and expertise in the precision cleaning and assembly of all containment hardware. Jerry Mulder executed the laser welding and Jim Okuno conducted the leak checks and Domenic Aldi conducted the mechanical tests. At GSFC: Many kudos to Chris Johnson and Ryan Wilkinson for fabrication of the doping manifold, and Wilkinson again for technical assistance during doping and executing the pinchoff operations. Marvin Noriega also assisted with pinch-off. Jeff Mobley did the final cleaning and packaging of the assembled flight units prior to delivery to JPL. Thanks also to Dennis Nehl for thermal monitoring during the doping procedure. Rob Taminelli provided a specialty configuration for the clean room operations at GSFC and provided an extra set of hands during the doping and pinch-off procedures. Amy McAdam assisted with XRD and XRF analysis of the verification brick. Melissa Floyd assisted with GCMS analysis of the verification brick. At HP Technical Ceramics: Tim Wang went beyond the call of duty for a vendor providing excellent technical advice and execution of extraordinary cleanliness measures during fabrication of the bricks.

Open Access This article is distributed under the terms of the Creative Commons Attribution License which permits any use, distribution, and reproduction in any medium, provided the original author(s) and the source are credited.

\section{References}

R.C. Anderson, L. Jandura, A.B. Okon, D. Sunshine, C. Roumeliotis, L. Beegle, J. Hurowitz, B. Kennedy, D. Limonadi, S. McCloskey, M. Robinson, C. Seybold, K. Brown, J. Crisp, Collecting powdered samples in Gale crater, Mars: an overview of the Mars science laboratory sample. Acquisition, sample processing, and handling system. Space Sci. Rev. (2012). doi:10.1007/s11214-012-9898-9

K. Biemann, J. Oro, P. Toulmin III, L.E. Orgel, A.O. Nier, D.M. Anderson, P.G. Simmonds, The search for organic substances and inorganic volatile compounds in the surface of Mars. J. Geophys. Res. 82, 4641-4658 (1977)

D.F. Blake, D. Vaniman, C. Achilles, R. Anderson, D. Bish, T. Bristow, C. Chen, S. Chipera, J. Crisp, D. Des Marais, R.T. Downs, J. Farmer, S. Feldman, M. Fonda, M. Gailhanou, H. Ma, D. Ming, R. Morris, P. Sarrazin, E. Stolper, A. Treiman, A. Yen, Characterization and calibration of the CheMin mineralogical instrument on Mars science laboratory. Space Sci. Rev. (2012). doi:10.1007/s11214-012-9905-1

N.A. Cabrol, E.A. Grin, H.E. Newsom, R. Landheim, C.P. McKay, Hydrogeologic evolution of Gale Crater and its relevance to the exobiological exploration of Mars. Icarus 139, 235-245 (1999)

D.A. Ellis, T.N. Cahill, S.A. Mabury, I.T. Cousins, D. Mackay, Partitioning of organifluorine compounds in the environment, in The Handbook of Environmental Chemistry, ed. by A.H. Neilson. Organofluorines, vol. 3 (Springer, Berlin, 2002), pp. 64-82. Part N 
J.P. Grotzinger, J. Crisp, A.R. Vasavada, R.C. Anderson, C.J. Baker, R. Barry, D.F. Blake, P. Conrad, K.S. Edgett, B. Ferdowsi, R. Gellert, J.B. Gilbert, M. Golombek, J. Gomez-Elvira, D.M. Hassler, L. Jandura, M. Litvak, P. Mahaffy, J. Maki, M. Meyer, M.C. Malin, I. Mitrofanov, J.J. Simmonds, D. Vaniman, R.V. Welch, R.C. Wiens, Mars science laboratory mission, science investigations. Space Sci. Rev. (2012). doi:10.1007/s11214-012-9892-2

P.M. Mahaffy, C.R. Webster, M. Cabane, P.G. Conrad, P. Coll et al., The sample analysis at Mars investigation and instrument suite. Space Sci. Rev. (2012). doi:10.1007/s11214-012-9879-Z

D. Ming, R.V. Morris, R. Woida, B. Sutter, H.V. Lauter, C. Shinohara, Mars 2007 Phoenix scout mission organic free blank (OFB): method to distinguish Mars organics from terrestrial organics. J. Geophys. Res. 113, 17 (2008)

M.J. Mumma, G.L. Villanueva, R.E. Novak, T. Hewagama, B.P. Bonev, M.A. DiSanti, A.M. Mandell, M.D. Smith, Strong release of methane on Mars in northern summer 2003. Science 323(5917), 1041-1045 (2009)

R. Navarro-Gonzalez, E. Vargas, J. de la Rosa, A.C. Raga, C.P. McKay, Reanalysis of the Viking results suggests perchlorate and organics at midlatitudes on Mars. J. Geophys. Res. 115, E12010 (2010)

H.B. Niemann, S.K. Atreya, S.J. Bauer, K. Biemann, B. Block, G.R. Carignan, T.M. Donahue, R.L. Frost, D. Gautier, J.A. Haberman, D. Harpold, D.M. Hunten, G. Israel, J.I. Lunine, K. Mauersberger, T.C. Owen, F. Raulin, J.E. Richards, S.H. Way, The gas chromatograph mass spectrometer for the Huygens probe. Space Sci. Rev. 104, 553-591 (2002)

S.M. Pelkey, B.M. Jakosky, Surficial geologic surveys of Gale crater and Melas Chasm, Mars: integration of remote sensing data. Icarus 160, 228-257 (2002)

S.M. Pelkey, B.M. Jakosky, P.R. Christensen, Surficial properties in Gale crater, Mars, from Mars Odyssey THEMIS data. Icarus 167, 244-270 (2004)

D.A. Skoog, D.M. West, F.J. Holler, S.R. Crouch, Fundamentals of analytical chemistry, 8th edn. (Brooks/Cole, Belmont, 2004), 992 pp.

L.-W. Tsai, Mechanism Design: Enumeration of Kinematic Structures According to Function (CRC Press, Boca Raton, 2001). Chap. 6

A.R. Vasavada, A. Chen, J.R. Barnes, D.P. Burkhart, B.A. Cantor, A.M. Dwyer-Cianciolo, R.L. Fergason, D.P. Hinson, H.L. Justh, D.M. Kass, S.R. Lewis, M.A. Mischna, J.R. Murphy, S.C.R. Rafkin, D. Tyler, P.G. Withers, Assessment of environments for Mars science laboratory entry, descent, and surface operations. Space Sci. Rev. (2012). This issue 